\title{
MASCULINIDADES E PSICODRAMA: CONTRIBUIÇÕES DA TÉCNICA DO DESDOBRAMENTO DO EU
}

\author{
Lucas Schweitzer ${ }^{1,2^{*}}$ (D), Luciana Moskorz Kersbaumer² (D)
}

\begin{abstract}
RESUMO
Este artigo tem como objetivo compreender os benefícios da utilização da técnica do desdobramento do eu em demandas psicológicas relacionadas às masculinidades em um processo de psicodrama bipessoal. Por meio de uma pesquisa-ação com um homem adulto, foi possível identificar conservas culturais vinculadas ao papel de gênero. Observou-se uma suposta obrigatoriedade de vigor físico e psicológico, de não demonstração de sentimentos, vulnerabilidades e sensibilidade, bem como uma exigência constante de trabalho e produtividade. Ao se fazer os eus internos do protagonista contracenarem por meio da técnica do desdobramento do eu, possibilitou-se o encontro com caminhos efetivos de busca da saúde biopsicossocial, por vezes integrando e/ou acionando outros eus para atuarem diante dos desafios cotidianos.
\end{abstract}

PALAVRAS-CHAVE: Psicodrama bipessoal; Eus internos; Conservas culturais.

\section{MASCULINITIES AND PSYCHODRAMA: CONTRIBUTIONS OF THE SELF UNFOLDING TECHNIQUE}

\begin{abstract}
This article aims to understand the benefits of using the self unfolding technique in psychological demands related to masculinities in a bipersonal psychodrama process. Through action research with an adult man, it was possible to identify cultural conserves linked to gender role. There is an assumption that masculinity requires physical and psychological vigor, not showing feelings, vulnerabilities and sensitivity, as well as a constant demand for work and productivity. By making the protagonist's internal selves act together through the self unfolding technique, it was possible to encounter effective paths in search of biopsychosocial health, sometimes integrating and/or triggering other selves to act in the face of daily challenges.
\end{abstract}

KEYWORDS: Bipersonal psychodrama; Internal selves; Cultural conserves.

\section{MASCULINIDADES Y PSICODRAMA: CONTRIBUCIONES DE LA TÉCNICA DE DESDOBLAMIENTO DEL YO}

\section{RESUMEN}

Este artículo tiene como objetivo comprender los beneficios de utilizar la técnica de desdoblamiento del yo en demandas psicológicas relacionadas con las masculinidades en un proceso de Psicodrama Bipersonal. A través de una investigación con un hombre adulto, fue posible identificar las acciones culturales vinculadas al rol de género. Se observa una supuesta exigencia de vigor físico y psicológico, de no manifestar sentimientos, vulnerabilidades y sensibilidad, así como una constante demanda de trabajo y productividad. Al hacer que mis yo internos actuaran como protagonistas a través de la técnica de desdoblamiento del yo, fue posible encontrar caminos efectivos para la búsqueda de la salud biopsicosocial, integrando en ocasiones y / o desencadenando otros yo para actuar ante los desafíos cotidianos.

PALABRAS CLAVE: Psicodrama bipersonal; Yo internos; Acciones culturales.

\footnotetext{
1.Universidade Federal de Santa Catarina ${ }_{R}$ - Programa de Pós-Graduação em Psicologia - Departamento de Psicologia -
} Florianópolis (SC), Brasil.

2. Viver Mais Psicologia - Especialização e Formação em Psicodrama - Tubarão (SC), Brasil.

*Autor correspondente: lucass.schweitzer@gmail.com

Recebido: 24 Jul. 2021 | Aceito: 28 Out. 2021

Editora de seção: Marília Bruhn 


\section{INTRODUÇÃO}

O psicodrama bipessoal é uma modalidade psicodramática adaptada à situação a dois, diretor e protagonista (Cukier, 1992), em que se faz uso de diferentes técnicas do psicodrama, dentre as quais há a técnica do desdobramento do eu (Rodrigues, 2008). Essa técnica traz contribuições ao possibilitar a interação dos diferentes eus que habitam o psiquismo humano e que podem estar em convergência ou divergência, potencialmente produzindo a sensação de um conflito no mundo interno das pessoas (Cukier, 1998; Dias, 2006). Por meio dessa técnica, possibilita-se o confronto e/ou o diálogo entre eus com versões opostas que, no caso específico deste artigo, são relacionadas diretamente às masculinidades e, muitas vezes, permeadas por conservas culturais não saudáveis.

Sobre a construção da masculinidade na sociedade contemporânea, parte-se do pressuposto que a ela são circunscritos paradigmas históricos e sociais nos quais se definem os atributos que significam o masculino (Beiras et al.,2007). Dessa forma, parte-se do entendimento que os papéis sociais de gênero são ditados e aprendidos pela e na sociedade e desempenhados por cada sujeito, com base em sua história de vida e do seu meio sociocultural (Conceição \& Auad, 2010).

$\mathrm{Na}$ contemporaneidade ocorre uma gradativa modificação de valores até então estabelecidos como inquestionáveis, tais como o da sexualidade e dos papéis de gênero (Conceição \& Auad, 2010). Essa questão é atrelada ao atual momento histórico, em que há um conjunto de transformações na esfera política, econômica e social. Aspectos tradicionalmente estabelecidos e relacionados às relações de gênero vêm sendo pauta de debates, inclusive pela emergência do ingresso das mulheres na vida pública e do movimento feminista, o que vem produzindo significativas alterações nos códigos e modelos comportamentais (Bento, 1999).

O funcionamento e os modelos de famílias, a noção de representação da mulher como inferior ao homem, a vinculação da sexualidade à reprodução, o lugar da virgindade nas relações e o código moral assimétrico entre gêneros são alguns exemplos de conceitos que vêm sendo questionados. Nesse sentido, profundas discussões fundamentadas na ideia de direitos de escolha dos seres humanos vêm sendo realizadas, o que evidencia o entendimento de que todos são livres e autônomos no que tange aos seus destinos. Ao passo disso, vem ocorrendo um movimento de reorganização do masculino, com novas formas de expressão da subjetividade. Trata-se de um processo lento e mobilizador de debates sobre os padrões de masculinidade, marcado por conflitos existenciais (Bento, 1999).

Aidar (2007) discute o trajeto da construção da identidade masculina a partir do psicodrama e ressalta a forma como as conservas culturais definem parâmetros de conduta através das interrelações estabelecidas pelo indivíduo. Ele assevera que as mudanças sociais motivam transformações nas conservas culturais e têm levado ao aparecimento de uma crise na masculinidade, relacionada a um movimento de retomada da espontaneidade no desempenho dos papéis.

Dalmiro Bustos (2003) discute a condição de ser homem na sociedade, demarcando suas influências históricas, sociais, religiosas e mitológicas. $\mathrm{O}$ autor afirma que, ao homem, é endereçada, quase que de forma naturalizada, a "capacidade de ser líder, provedor, decidido, ousado, destemido e, fundamentalmente, potente", o que supostamente definiria "seu valor como humano" (Bustos, 2003, p. 65). Essas situações levantam o debate sobre como é, para o homem contemporâneo, conviver com essas conservas culturais tão estabelecidas, que exigem constante monitoração (Aidar, 2007) e, ao mesmo tempo, relacionar-se com uma realidade social com profundas alterações.

Todos os elementos expostos demonstram a atualidade e a relevância de se estudar os benefícios da utilização da técnica do desdobramento do eu em demandas psicológicas relacionadas às masculinidades para homens inseridos em processos de psicodrama bipessoal, em especial ao se considerar a implicação do psicodrama com a transformação social e da utilidade de seu arcabouço teórico e metodológico para a construção de uma sociedade e de sujeitos mais espontâneos e criativos.

O interesse por este tema surgiu de experiências em sessões de psicodrama junto a homens de diferentes faixas etárias. Nessas sessões, observou-se a relevância do uso da técnica do desdobramento do eu (Rodrigues, 2008) ao longo dos processos de psicodrama bipessoal, nos casos de homens com demandas psicológicas relacionadas às masculinidades. Diversos discursos foram identificados sob a forma de padrões sociais conhecidos e, por vezes, cristalizados em conservas culturais não saudáveis, que suscitaram o interesse na temática. 
Dentre as obras dos principais autores do psicodrama, é possível citar o Manual para um homem perdido, em que Dalmiro Bustos (2003) faz importantes contribuições para a compreensão do significado de ser homem no século XXI. Ademais, em Silva e Danielski (2018) identificou-se, a partir da técnica do átomo social, uma reconfiguração sociométrica, com alterações nas redes relacionais do cônjuge masculino após o estabelecimento do vínculo conjugal, com importantes contribuições no que se refere a construção do papel de homem nas relações.

Espera-se que essa produção possa contribuir com o conhecimento científico sobre o tema, bem como com a prática profissional de psicodramatistas interessados na temática. Objetiva-se que estes possam ser cada vez mais bem instrumentalizados para os atendimentos junto às demandas aqui discutidas. Para a sociedade, que possa ser útil para trazer reflexões, estranhamentos e questionamentos de algumas verdades pouco questionadas até então.

\section{MÉTODOS}

A presente pesquisa caracteriza-se como descritiva, visto que tem o objetivo de descrever as características do fenômeno ou contextos, fatos, situações, caraterísticas e problemas (Gil, 2002; Sampieri et al., 2006). A abordagem escolhida foi a qualitativa, cujo objetivo é conhecer as singularidades e os significados, com atenção para a intensidade dos fenômenos e suas dimensões socioculturais (Minayo, 2014). Nesse sentido, parte-se do pressuposto de que o conhecimento se desenvolve dentro de um contexto relacional e deve considerar a totalidade do processo de investigação, enfatizando-se um caráter sócio-histórico e subjetivo na produção do saber (Monteiro et al., 2006). Cabe salientar que, na metodologia científica socionômica, ocorre um envolvimento existencial do psicodramatista-pesquisador com a experiência, cabendo a ele distanciamento reflexivo, a partir da premissa de corresponsabilidade em todo o processo da pesquisa (Wechsler, 2007).

A fim de atingir o objetivo de pesquisa, optou-se pela utilização da pesquisa-ação, modelo bastante recorrente em pesquisas sociopsicodramáticas, em que, por meio da participação implicada, objetiva-se as construções e transformações individuais, sociais e/ou comunitárias (Contro, 2009). A pesquisa foi baseada em estudos de um caso clínico por meio da descrição e da análise de sessões em que se fez o uso da técnica estudada no presente artigo e em que há presença de demandas relacionadas às masculinidades.

A escolha do participante do estudo foi realizada de forma não aleatória e os critérios de inclusão são os seguintes: paciente homem, adulto, ou seja, com idade maior de 18 anos, que concordou com a participação voluntária na pesquisa e inserido em processo de psicoterapia, na qual foram identificados elementos relacionados à temática do presente estudo. Ao participante foi dado o nome fictício de Paulo. Ele tem 35 anos, é casado, trabalha como gerente de supermercado, tem ensino superior como escolaridade e está em psicoterapia há três semanas.

A coleta de dados foi realizada por meio de recortes de sessões, a partir dos registros dos atendimentos realizados pelo psicoterapeuta, em conformidade com a resolução CFP no 01/2009 (Brasil, 2009), decorrentes de atendimentos realizados ao longo do ano de 2020. Os atendimentos, com duração de 50 minutos cada, ocorreram em horários agendados previamente junto ao paciente, na sala de atendimento psicológico do consultório particular do psicoterapeuta, localizado no sul do Brasil. O espaço da sala de atendimento é constituído de alguns móveis, dentre os quais: uma poltrona, um sofá, armários com livros e uma diversidade de almofadas, de diferentes tamanhos e cores, que são dispostas em um dos cantos do tapete, que fica na parte central da sala.

Quanto à análise, de acordo com Wechsler (2007), os resultados da pesquisa socionômica estão vinculados à situação nos quais foram coproduzidos, dentro do contexto apresentado. A análise dos dados da presente pesquisa foi realizada à luz dos diversos conceitos teóricos e epistemológicos da socionomia, com base no referencial teórico-técnico apresentado.

A análise dos dados foi elaborada considerando as etapas de uma sessão de psicodrama bipessoal, ou seja, aquecimento, dramatização e compartilhamento (Cukier, 1992). Conforme Rodrigues (2008), as intervenções realizadas foram de foco psicoterápico, com o objetivo de superação de dificuldades. Dessa forma, ateve-se aos contextos (social, grupal e dramático), instrumentos (direção, protagonista, cenário) e técnicas (desdobramento do eu, inversão de papéis, solilóquio, espelho, entre outras) do psicodrama. 
Foi realizada a estratégia de análise por meio do processamento, momento em que ocorre a descrição e a reflexão sobre o que ocorreu ao longo da sessão, em situação posterior a ela, buscando compreender o sentido dos acontecimentos mais profundamente, de forma intelectual/racional. A principal forma utilizada foi o processamento por meio do protagonista, a fim de compreender o evento psicodramático tomando o protagonista como eixo central (Aguiar \& Tassinari, 1999).

A utilização dos dados obtidos com as sessões de psicodrama foi condicionada à assinatura de um Termo de Consentimento Livre e Esclarecido (TCLE), assinado pelo próprio participante. Em conformidade com a Resolução 466/2012 do Conselho Nacional de Saúde, a pesquisa foi submetida e aprovada pelo Comitê de Ética em Pesquisa com Seres Humanos (Brasil, 2012).

\section{ANÁLISE DE DADOS}

Paulo é um homem adulto, com 35 anos de idade. É casado e mora com a esposa e três filhos. Único responsável pelo sustento da família, trabalha como gerente no supermercado dos seus pais. Mantém relação muito próxima com eles, tendo em vista que é considerado "a cabeça" ou a "coluna de sustentação" do local, ou seja, é o principal responsável pela gestão de praticamente todas as atividades e recursos. É nesse local que passa a maior parte dos seus dias. Relata que sempre trabalhou muito para sustentar a família e ajudar seus pais (donos do negócio). O paciente tem uma irmã mais nova. É natural e morador de uma cidade de médio porte do sul do Brasil.

O paciente vem ao consultório de psicologia com a demanda de estresse pós-traumático, cujo diagnóstico foi realizado anteriormente por um médico psiquiatra. Ao longo das sessões são trabalhadas questões relacionadas a um acidente de carro sofrido há cerca de quatro meses. Cabe salientar que o acidente ocorreu durante o horário de trabalho. No momento da sessão relatada, o paciente estava no início do acompanhamento, em sua terceira sessão. Esse acompanhamento foi a sua primeira experiência com psicoterapia.

Considerando que o caso se refere a uma demanda relacionada ao transtorno de estresse pós-traumático (TEPT), apesar de não ser o foco específico desta exposição, é importante mencionar a compreensão psicodramática para esse fenômeno, que vai para além dos critérios diagnósticos dos manuais de psicopatologia ${ }^{1}$ - ainda que estes não sejam desconsiderados. Aqui, parte-se do entendimento de que o estresse pós-traumático ocorre diante de uma ameaça muito grande ou diante do embotamento da espontaneidade, que produz dificuldades para o sujeito manifestar criatividade, impedindo ou produzindo dificuldades no exercício do papel, ao não produzir respostas adequadas às situações ameaçadoras. Quanto mais ameaçadoras forem as situações vividas, mais poderão comprometer a espontaneidade, a criatividade, a sensibilidade e, por consequência, a saúde mental das pessoas, devido ao impedimento do livre desempenho dos papéis (Bernardes et al., 2018).

No início da sessão, é realizado o aquecimento inespecífico do paciente por meio do livre diálogo sobre os últimos acontecimentos de sua vida. Essa parte da sessão tem o objetivo de centralizar a atenção, diminuir estados de tensão e facilitar a interação entre o diretor e o paciente (Rojas-Bermúdez, 2016).

Paulo relata que, após o acidente, vem se sentindo menos produtivo, apesar de manter todas as atividades de rotina. Percebe que sua vida estava centrada unicamente no trabalho e isso o incomoda, mas que "o ideal seria voltar a ser produtivo como antes [sic]". Sempre foi muito forte e deseja se manter assim, no entanto está com dificuldades de retomar as coisas como eram anteriormente. Observa que sintomas de ansiedade vêm ocorrendo com frequência no seu trabalho e tem receio de não dar conta de suas obrigações.

Ao longo da fala do paciente observa-se um conflito entre as versões de si de antes do acidente e do presente momento. A partir da leitura de Dias (2006), a situação exposta pode ser considerada uma divisão interna, que ocorre quando existem "duas ou mais forças conflitantes dentro do mundo interno do indivíduo" (p. 155). Além disso, pode manter relações com a valorização social de um grande investimento na virilidade laborativa por parte dos homens, o que, em sua ausência, costumeiramente produz dificuldades com autoestima (Baére \& Zanello, 2020).

1.Resumidamente, o TEPT diz respeito à reação aguda a eventos traumáticos, conforme a Classificaşão Estatística Internacional de Doenças e Problemas Relacionados à Saúde, CID-10 (Organização Mundial da Saúde, 1993), e o Manual Diagnóstico e Estatístico dos Transtornos Mentais (DSM-5-TR) (American Psychiatric Association, 2014). Os critérios psicodiagnósticos envolvem resposta de pavor e medo, revivência, evitação e excitabilidade fisiológica aumentada ao tempo e prejuízo funcional (Bernardes et al.,2018). 
É utilizado um aquecimento inespecífico em movimento, indo além do verbal, reconectando o paciente com o corpo por meios como a respiração e a consciência corporal (Cukier, 1992). O protagonista é solicitado a fechar os olhos, prestar atenção em seu corpo, respirar fundo por algumas vezes e entrar em contato com seu $e u$ anterior ao acidente, encontrando cores que simbolizem sua rotina. A escolha pelo uso das cores ocorre para adentrar o mundo interno do paciente, permitindo a comunicação do mesmo através deste meio expressivo (Rojas-Bermúdez, 2016).

$\mathrm{O}$ diretor conduz Paulo a deixar que uma ou mais cores ganhem protagonismo no seu mundo interno. Relata que as cores são opacas, principalmente tons de cinza. Após dar voz a este primeiro eu, é solicitado que busque pela outra versão de si mesmo, que estaria brigando com este de antes do acidente. A indicação da busca por cores que simbolizem esse $e u$ também é realizada. Ele afirma que é uma forma colorida e que a considera bonita, porém um pouco assustadora.

Nessa etapa, como aquecimento específico, o diretor conduz a situação do mundo interno do paciente para o externo, no palco psicodramático, preparando-o para deixá-lo nas melhores condições para a dramatização, construir um contexto dramático e a definir os personagens que farão parte da cena (Rojas-Bermúdez, 2016). Para isso, faz-se uso do como se, ou seja, o espaço da realidade suplementar, uma realidade extra em que é possível experimentar papéis num contexto continente, onde é possível e permitido refazer caminhos e cocriar (Nery, 2014).

Dessa forma, segue-se a etapa de dramatização da sessão psicodramática, em que as descrições passam a ser vividas, adquirindo existência real, em que o espaço subjetivo do paciente é mostrado (Silva Filho, 2015). Utilizando-se das almofadas dispostas no chão do consultório psicológico, conforme orientação do diretor, Paulo escolhe a de cor cinza claro para o $e u$ de antes do acidente e, outra, com várias cores e formas, para o momento presente, sendo orientado a escolher um eu para começar. O protagonista opta pelo eu cinza. Então, toma o papel do eu cinza e o diretor passa a realizar a entrevista neste papel. Nesse procedimento, o terapeuta entrevista o personagem interno incorporado pelo paciente, a fim de estabelecer uma estratégia para que novos aportes psicodinâmicos sejam trazidos ao caso (Fonseca, 2018).

A partir dos questionamentos do diretor, Paulo comenta estar se sentindo sempre um pouco cansado, mas não conta isso para ninguém. Ele afirma:

- Sou responsável pelo negócio dos meus pais e, além disso, sou o homem da família. Preciso sustentar minha esposa e filhos. Preciso estar forte. Eu tenho que ser o pilar da família.

O diretor pergunta desde quando existe esse $e u$. Paulo responde que é desde pequeno, mas que aumentou em intensidade quando se casou e passou a ser responsável pela família. Relata que sempre tem olhado para frente, sem pensar muito em problemas. Complementa que trabalha, paga as contas, resolve os problemas e "não dá tempo para mais nada [sic]".

O diretor solicita que, junto ao eu cinza, faça uma imagem corporal que represente a emoção que sente. Esse direcionamento é dado pois a comunicação por meio do corpo tem o objetivo de ir para além das palavras, desvelando além do que é falado e sentido, mas também visando potencializar a capacidade expressiva corporal (Giro et al., 2015). As esculturas ou imagens permitem dar maior concretude a conteúdos simbólicos, dando-lhes vida (Cukier, 1992).

Com isso, Paulo afirma que parece não ter forma fixa — faz uma imagem em movimento, de olhos fechados. É solicitado um solilóquio da escultura, ou seja, a expressão em voz alta do que estava mantido, de forma inquieta, apenas em pensamento (Cukier, 1992; Fonseca, 2008), em que ele relata:

— Preciso ir logo, não dá tempo de sentir, nem de ver. Tenho que fazer as coisas.

A partir dessas falas do protagonista, é possível observar uma sobrecarga relacionada às muitas exigências que ainda recaem sobre ele, enquanto homem, para alcançar as expectativas lançadas pela sociedade, as quais, por vezes, são reproduzidos de forma naturalizada. Isso ocorre diante dos papéis sociais de gênero, presentes no discurso do protagonista, que são "ditados e aprendidos pela e na sociedade e desempenhados por cada indivíduo, de acordo com sua história de vida e com o contexto em que vive" (Conceição \& Auad, 2010, p. 132). 
O protagonista não questiona o fato de ser o único responsável pelo sustento familiar, entendendo isso como uma obrigação dada a priori, advinda pelo fato de ter nascido homem. Sobre isso, Bustos (2003) traz, por repetidas vezes, uma frase de sua pesquisa junto a homens: "o homem é vigor ou nada", ou seja, que o vigor, no caso, relacionado diretamente à capacidade produtiva e econômica de Paulo, definiria sua condição de ser homem. Nessa constituição, ser homem estaria com sua significação diretamente ligada à capacidade de ser provedor (Bustos, 2003) e, em sua ausência, seu valor supostamente seria perdido, causando sofrimento ao indivíduo. No caso, observa-se a forma como essas conservas culturais, rígidas e cristalizadas, têm gerado sofrimento ao protagonista, cabendo ao diretor promover reflexões e questionamentos a respeito delas a partir da ação psicodramática.

Em continuidade à dramatização é indicado que o protagonista olhe de fora para a escultura elaborada, do eu cinza. Nesse caso, utiliza-se a técnica do espelho, que permite a função observadora do eu por meio do olhar para os aspectos presentes na cena e, por consequência, que reflita sobre a sua reação frente a eles (Cukier, 1992). Paulo afirma que o eu cinza está sobrecarregado, e não vê saídas para a situação. Que há muitas preocupações e obrigações. Tem vontade de pedir calma a ele, o que é estimulado a fazer. Então, ainda em espelho, ele assevera:

— Tenha calma. Você tem muito o que fazer, eu sei, mas não precisa dar conta de tudo sozinho. Não é obrigado a nada e não está sozinho.

O diretor solicita que o eu observador olhe para o eu colorido e diga o que percebe. Ele comenta:

— Tem muitas cores e possibilidades.

Então o diretor utiliza a técnica da inversão de papéis, em que o paciente é levado a representar um papel de alguém a quem está se referindo, seja real ou imaginário (Monteiro, 1993). Essa técnica tem por objetivo produzir o insight ou a compreensão integradora do protagonista (Menegazzo, 2019). Na dramatização, inicia-se a inversão pelo eu colorido, que afirma estar aprendendo coisas que não sabia. Gosta do seu trabalho, mas também quer estar com seus filhos, ter tempo e saúde. Assevera seu desejo de viajar e ter lazer. Quer viver mais, de forma leve. Relata:

— Aprendi com o acidente que preciso viver, que não dá para somente trabalhar.

O eu colorido é orientado a olhar para o eu cinza e, ao olhá-lo, que veja ele em ação. É solicitado que diga o que percebe para ele:

— Você não está nem olhando o que está fazendo. Muito apressado, correndo. Precisa parar um pouco, tomar mais cuidado.

Em seguida, o eu cinza responde para o eu colorido:

— Não é certo. Você precisa trabalhar, você é o homem da casa, chefe de família. Você está inventando moda, e é irreal. As coisas que conquistou não permitem pausas.

A fim de aprofundar a percepção interna do protagonista (Bustos, 1999), o diretor pede que Paulo feche os olhos e veja tudo que conquistou com o eu cinza em uma fotografia. Diz que vê sua família, bonita e feliz, e que sente muito orgulho do que vê. É questionado, então, sobre o que eles, inclusive Paulo, precisam. Ele responde que todos precisam de estabilidade, mas também de paz, harmonia e, principalmente, tempo para viver. Assevera, com a presença de choro, que não é somente de bens materiais e dinheiro que precisam. Que a vida não é somente trabalho, pois, além de trabalhador, ele também é pai, marido, filho, amigo, irmão, dentre outros papéis. 
Essa conclusão do protagonista é condizente com a noção de saúde mental no psicodrama, relacionada não somente à qualidade, mas também à quantidade de papéis desempenhados. O número de papéis representa a quantidade de vínculos nos quais o protagonista está envolvido, o que, ao perceber e colocar em prática, contribui para sua saúde biopsicossocial (Bernardes et al., 2018).

Em continuidade à sessão, o eu colorido reforça que eles precisam descansar, que amam brincar com os filhos e que, apesar de não quererem admitir, gostariam de trabalhar menos e de ter lazer. Então, a fim de dar voz ao conteúdo não verbalizado do paciente (Cukier, 1992), o diretor faz um duplo:

— Nós queremos e podemos descansar!

O protagonista repete espontaneamente a frase logo após, indicando concordar com a fala. Nessa direção, Nery (2014) afirma que confirmação do cliente é um importante princípio do duplo. Isso ocorre pois o objetivo dessa técnica é ajudar o paciente na constatação de emoções e na compreensão da afetividade que envolve sua ação, além de conduzir a uma reflexão sobre a ação que contemple maior contato com o interior do protagonista.

Em resposta ao eu colorido, o eu cinza afirma achar possível e que podem tentar juntos. Então, os dois eus dialogam a fim de planejar como farão para descansar e, ao mesmo tempo, garantir a subsistência da família. Decidem que conversarão sobre a possibilidade de a esposa ter alguma renda e colocarem os filhos menores na creche. Também decidem baixar o padrão de gastos, guardar dinheiro para passeios e viagens e dividir tarefas com os outros trabalhadores do supermercado, pois não precisam dar conta de tudo sozinhos.

Por fim, o diretor pede que o eu observador diga o que percebeu, analisando a cena do lado de fora. Relata que chegou a uma conclusão. De olhos fechados, é indicado que crie um personagem que represente a conclusão. Afirma que possui várias cores, mas que não são assustadoras, pois também há a cor cinza em meio a elas. Vê este como um eu possível. Dessa forma, observa-se uma saída espontânea e criativa para o conflito exposto ao longo da dramatização, de modo que uma nova resposta a uma situação antiga foi possível por meio do ato de criar (Silva Filho, 2015).

Com a finalização da dramatização é realizado um breve compartilhamento, momento dedicado à exposição de sentimentos e pensamentos sobre as vivências ocorridas durante a dramatização (Silva Filho, 2015). O paciente afirma que não estava conseguindo vislumbrar saída para a situação presente e que considerava que teria que conviver com este conflito para sempre. Agora entende que há possibilidade de construir uma terceira possibilidade para além daquelas que já conhecia.

Por meio da utilização da técnica do desdobramento do eu e de todo o arcabouço técnico e teórico do psicodrama, observa-se a possibilidade de clarificar os diferentes eus do paciente. Assim, foi iniciada a busca por equilíbrio entre conflitos e divergências internas por meio de ações e caminhos plausíveis a serem realizadas (Ladislau, 2019), encontrando uma saída mais saudável para a situação de sofrimento trazida.

Cabe salientar que, nessa sessão, o diretor não realiza o compartilhamento de suas experiências pessoais. Isso ocorre pois essa exposição não se faz fundamental em todos os casos e sessões, tendo em vista que o compartilhar do diretor deve sempre ser pensado em prol da pessoa atendida, sendo condicionada a uma margem de segurança e disponibilidade sincera por parte do diretor. No caso, faz-se aquilo que é considerado como fundamental para Bustos (1990): "sentir suas experiências em um grau de disponibilidade que lhe permita compreender empaticamente o sofrimento do outro” (p. 113).

Outro elemento de importante apontamento é que, na sessão seguinte à presente, Paulo relata uma conversa realizada com a esposa a respeito de suas conclusões, na qual discutiram sobre os sentimentos de Paulo e a sobrecarga que vinha sentindo, efetivando-se algumas alterações na rotina do casal. Planejam estar mais tempo junto à família, diminuir a carga de trabalho e realizar algumas atividades de esporte e lazer. Paulo também narra que pretende ter uma conversa com seus pais a respeito de uma organização de tarefas no supermercado da família. Nesse sentido, é possível observar que a saída criativa realizada no consultório reverberou em ações práticas do cotidiano, potencialmente produtoras de saúde mental para o paciente. Ademais, à medida que essas estratégias foram sendo adotadas, também seus sintomas de ansiedade e estresse, mesmo que ainda presentes, diminuíram progressivamente. 
Por fim, com base na exposição e discussões sobre o caso relatado, percebe-se a presença de conteúdos para além de um dos mitos citados por Bustos (2003) como sendo diretamente relacionado às masculinidades: o do Sísifo. Nesse mito, o personagem foi condenado ao castigo de carregar um rochedo até o topo de uma montanha, sendo que o rochedo sempre lhe escapa ao chegar ao final do seu objetivo. O castigo dado por Zeus diz respeito ao "trabalho contínuo de modo que não possa nunca usufruir do seu labor" (Bustos, 2003, p. 163). Esse mito se mostra atual ao se considerar que, ainda hoje, "o fazer domina o ser de maneira alarmante" (p. 163), em um modelo conservado que privilegia a capacidade produtiva e o naturaliza.

\section{CONSIDERAÇÕES FINAIS}

O presente artigo corrobora com o fato de que a psicoterapia, em especial na perspectiva socionômica, constitui-se em um espaço de compreensão e expressão, preferivelmente télico. O psicodrama bipessoal pode contribuir para a construção de uma sociedade mais justa e igualitária, comprometida em uma prática profissional engajada em direitos humanos e que entende os processos de mudança em que estão inseridas as pessoas que buscam por acompanhamento psicológico.

Cabe salientar que, em um espaço historicamente elitizado e, por vezes, entendido como neutro, como o de um consultório psicológico, também há caminho para um fazer político, engajado com a transformação social e com a transgressão de caminhos conservadores, fascistas e/ou autoritários. Ao encontro da proposta de Dedomenico e Merengué (2020), este artigo buscou estar de acordo com uma prática socionômica filiada a um espaço de resistência, não encobridora de formas de opressão.

No que tange ao objetivo de identificar as conservas culturais relacionadas às masculinidades no caso atendido, foram observadas conservas quanto ao papel de gênero, vinculadas a uma suposta obrigatoriedade de força e vigor físico e psicológico, bem como pressuposto de não demonstração de sentimentos, vulnerabilidades e sensibilidade. Além disso, também se pode identificar o lugar social de provedor e de chefe de família, por vezes produzindo uma exigência constante de trabalho, de ausência de descanso e produtividade. Percebeu-se que todas essas exigências, ainda que indicativas de privilégios históricos, também se constituem em produtoras de sofrimento psicológico. $\mathrm{O}$ psicodrama se torna relevante para a busca de caminhos mais saudáveis, com espontaneidade e criatividade a fim de construir novas alternativas ainda não conhecidas para os participantes de um processo psicoterápico.

Do ponto de visto técnico, foi possível descrever a aplicação da técnica do desdobramento do eu em um conflito relacionado às masculinidades, entendendo possibilidades de utilização, em especial no que se refere a possibilidades de apresentar diferentes eus internos e, por vezes, conflitantes e/ou contraditórios. Ao contracenarem, esses eus podem fazer com que os protagonistas encontrem caminhos efetivos em busca da saúde biopsicossocial, por vezes integrando-os e/ou acionando outros eus que possam atuar diante dos desafios cotidianos.

Foi possível identificar que essa técnica se mostrou um recurso potente para a construção e a reconstrução de saídas criativas e não cristalizadas, em especial enquanto caminho para a desconstrução de conservas culturais não saudáveis. Segundo Silva Filho (2015), essa é uma potencialidade do método psicodramático que, ao desencadear a criatividade da pessoa atendida, oportuniza a liberação de comportamentos e atitudes estereotipadas, de modo a criar novos papéis e liberar-se dos que estavam cristalizados.

Com bases nas diversas discussões levantadas, considera-se que a presente pesquisa traz contribuições relevantes para a prática profissional dos psicodramatistas, podendo qualificar seus fazeres, em especial ao considerar a necessidade de novas e constantes pesquisas sobre a utilização de técnicas em relação a demandas específicas, tais como às masculinidades. Além disso, entende-se sua relevância para a sociedade, em especial ao se considerar que a heteronormatividade e outras formas de controle excluem parcela da população e, também, que as violências de gênero se constituem em uma realidade demonstrada, cenário no qual o machismo encontra um lugar central de debate (Andrêo et al., 2016). Essas discussões são necessárias e urgentes e, de forma alguma, o psicodrama pode estar alheio a essas transformações sociais, uma vez que é uma ferramenta relacional. 
Enquanto limitação da pesquisa, ressaltamos que este artigo não contempla toda a diversidade de homens no que se refere à identidade de gênero, orientação sexual e toda a diversidade racial e social. Nesse sentido, novos estudos são necessários e possíveis. Como sugestão, além de contemplar tais diversidades, considera-se relevante a construção de pesquisas com diferentes especificidades relacionadas às masculinidades, tais como com o foco específico na sexualidade ou no trabalho, tendo em vista a relevância, a amplitude e a complexidade do objeto de estudo do presente artigo. Além disso, considera-se que a aplicação da técnica do desdobramento do eu pode se constituir em caminho efetivo para a construção de investigações junto a homens inseridos em grupos terapêuticos ou sociodramáticos, ou seja, não somente em processos de psicodrama bipessoal.

\section{CONTRIBUIÇÕES DOS AUTORES}

Conceitualização: Schweitzer L, Kersbaumer LM; Metodologia: Schweitzer L, Kersbaumer LM; Investigação: Schweitzer L; Redação - Primeira versão: Schweitzer L ; Redação - Revisão \& Edição: Schweitzer L; Supervisão: Kersbaumer LM.

\section{DISPONIBILIDADE DE DADOS DE PESQUISA}

Todos os conjuntos de dados foram gerados ou analisados no estudo em curso.

\section{FINANCIAMENTO}

Não aplicável.

\section{AGRADECIMENTOS}

Agradecimentos à Escola Viver Mais Psicologia, em especial às professoras Amanda Castro e Viviane Almeida, por suas contribuições ao artigo.

\section{REFERÊNCIAS}

Aguiar, M. \& Tassinari, M. (1999). O processamento em psicodrama. In: Almeida, W. C. (Org.). Grupos: A proposta do psicodrama (pp. 111-126). São Paulo: Ágora.

Aidar, J. (2007). Um novo homem: uma abordagem psicodramática da construção da identidade masculina. Revista Brasileira de Psicodrama, 15(2), 103-116.

American Psychiatric Association. (2014). Manual diagnóstico e estatístico de transtornos mentais: DSM-5 (5. ed.). Porto Alegre: Artmed.

Andrêo, C., Peres, W. S., Tokuda, A. M. P. \& Souza, L. L. de. (2016). Homofobia na construção das masculinidades hegemônicas: queerizando as hierarquias entre gêneros. Estudos e Pesquisas em Psicologia, 16(1), 46-67. https://doi. org/10.12957/epp.2016.24756

Baére, F. \& Zanello, V. (2020). Suicídio e masculinidades: uma análise por meio do gênero e das sexualidades. Psicologia em Estudo, 25, e44147. https://doi.org/10.4025/psicolestud.v25i0.44147

Beiras, A., Lodetti, A., Cabral, A. G., Toneli, M.J. F. \& Raimundo, P. (2007). Gênero e super-heróis: o traçado do corpo masculino pela norma. Psicologia E' Sociedade, 19(3), 62-67. https://doi.org/10.1590/S0102-71822007000300010

Bento, B. A. M. (1999). A (re)construção da identidade masculina. Revista de Ciências Humanas, (26), 33-50.

Bernardes, M. P., Nicolazzi, E. M. S., Scapini, T. \& Silva, N. (2018). Leitura psicodramática dos conceitos de transtorno de estresse pós-traumático (TEPT) e resiliência. Revista Brasileira de Psicodrama, 26(2), 36-45. https://doi. org/10.15329/2318-0498.20180025 
Brasil. Conselho Federal de Psicologia. (2009). Resolução CFP no 001/2009. Dispõe sobre a obrigatoriedade do registro documental decorrente da prestação de serviços psicológicos. Brasília: Conselho Federal de Psicologia. Disponível em: https://site.cfp.org.br/wp-content/uploads/2009/04/resolucao2009_01.pdf. Acesso em: 11 fev. 2021.

Brasil. Ministério da Saúde. (2012). Resolução no 466, de 12 de dezembro de 2012. Aprovar as seguintes diretrizes e normas regulamentadoras de pesquisas envolvendo seres humanos. Brasília: Diário Oficial da União. Disponível em: https://bvsms.saude.gov.br/bvs/saudelegis/cns/2013/res0466_12_12_2012.html. Acesso em: 10 fev. 2021.

Bustos, D. M. (1990). Perigo... Amor à vista! Drama e psicodrama de casais. Aleph.

Bustos, D. M. (1999). Novas cenas para o psicodrama: O teste da mirada e outros temas. Ágora.

Bustos, D. M. (2003). Manual para um homem perdido. Record.

Organização Mundial da Saúde. (1993). CID-10: Classificação estatística internacional de doenças e problemas relacionados à saúde. Edusp.

Conceição, M. I. G. \& Auad,J. C. (2010). Compreendendo as relações de gênero por meio da vivência sociodramática. Revista Brasileira de Psicodrama, 18(2), 129-143.

Contro, L. (2009). Veredas da pesquisa psicodramática: Entre a pesquisa-ação crítica e a pesquisa-intervenção. Revista Brasileira de Psicodrama, 17(2), 13-24.

Cukier, R. (1992). Psicodrama bipessoal: Sua técnica, seu terapeuta e seu paciente. Ágora.

Cukier, R. (1998). Sobrevivência emocional: As dores da infância revividas no drama adulto. Ágora.

Dedomenico, A. M. \& Merengué, D. (2020). Por uma vida espontânea e criadora: Psicodrama e política. Ágora.

Dias, V. R. C. S. (2006). Psicopatologia e psicodinâmica na análise psicodramática (Vol. 1). São Paulo: Ágora.

Fonseca, J. (2008). Psicodrama da loucura: Correlações entre Buber e Moreno (7. ed.). Ágora.

Fonseca, J. (2018). Essência e personalidade: Elementos de psicologia relacional. Ágora.

Gil, A. C. (2002). Como elaborar projetos de pesquisa (4. ed.). Atlas.

Giro, N. R., Oliveira,M.M.T.,Musleh,M.H.\& Prado,W.(2015). Ressonância corporal-uma proposta de intervenção psicodramática. Revista Brasileira de Psicodrama, 23(1), 51-59.

Ladislau, J. R. (2019). Os "eus" parciais como facilitadores no equilibrio do eu total [Trabalho de conclusão do curso de especialização]. Viver Mais Psicologia.

Menegazzo, C. M. (1995). Dicionário de psicodrama e sociodrama. Ágora.

Minayo, M. C. S. (2014). O desafio do conhecimento: Pesquisa qualitativa em saúde (14. ed.). Hucitec.

Monteiro, A. M., Merengué, D. \& Brito, V. (2006). Pesquisa qualitativa e psicodrama. Ágora.

Monteiro, R. (1993). Técnicas fundamentais do psicodrama. Brasiliense.

Nery, M. P. (2014). Vinculo e afetividade: Caminho das relações humanas. Ágora.

Rodrigues, R. (2008). Quadros de referência para intervenções grupais: Psicossociodramáticas. Revista Brasileira de Psicodrama, 16(1), 75-92.

Rojas-Bermúdez, J. G. (2016). Introdução ao psicodrama. Ágora.

Sampieri, R. H., Collado, C. F. \& Lucio, P. B. (2006). Metodologia da pesquisa (3. ed.). McGraw Hill.

Silva Filho, L. A. (2015). Doença mental, um tratamento possivel: Psicoterapia de grupo e psicodrama. Ágora.

Silva, B. F. \& Danielski, W. C. (2018). Vínculo conjugal: Um estudo psicodramático das redes relacionais do cônjuge masculino. Revista Brasileira de Psicodrama, 26(2), 23-35. https://doi.org/10.15329/2318-0498.20180024

Wechsler, M. P. F. (2007). Pesquisa e psicodrama. Revista Brasileira de Psicodrama, 15(2), 71-78. 